\title{
Efficacy of a toxicity-adjusted topotecan therapy in recurrent small cell lung cancer
}

\author{
R.M. Huber*, M. Reck\#, H. Gosse ${ }^{\star}$, J. von Pawel ${ }^{+}$, J. Mezger ${ }^{\S}$, J.G. Saal ${ }^{f}$, \\ R. Kleinschmidt**, C. Steppert ${ }^{\# \#}$ and H. Steppling ${ }^{\text {*⿻ }}$
}

ABSTRACT: The present prospective multicentre trial investigated whether topotecan, given at a starting dose of $1.25 \mathrm{mg} \cdot \mathrm{m}^{-2}$ with individual dose adjustment, can improve safety in patients with relapsed/refractory small cell lung cancer without loss of efficacy.

Patients received topotecan intravenously on days 1-5, every 21 days, for up to six courses. In the absence of relevant haematotoxicities, topotecan was increased to $1.5 \mathrm{mg} \cdot \mathrm{m}^{-2}$ and reduced to $1.0 \mathrm{mg} \cdot \mathrm{m}^{-2}$ in case of severe haematotoxicities.

Of 170 recruited patients, $73.2 \%$ had stage IV disease and $63.4 \%$ had platinum-containing pretreatment. Patients received a total of 521 courses. In $72.6 \%$ of those courses, the dose remained at $1.25 \mathrm{mg} \cdot \mathrm{m}^{-2}$; in $9.1 \%$ it was reduced and in $18.3 \%$ it increased. Overall response rate was $14.1 \%$ including one complete response; $28.8 \%$ had stable disease. Median duration of response was 13.6 weeks and median survival was 23.4 weeks. Clinical benefit was obvious for sensitive as well as for refractory patients. Haematotoxicity of grade 3 or 4 was clearly lower compared with the standard dose of $1.5 \mathrm{mg} \cdot \mathrm{m}^{-2}$.

In conclusion, topotecan at a dose of $1.25 \mathrm{mg} \cdot \mathrm{m}^{-2}$ appears to be as effective as the dose of $1.5 \mathrm{mg} \cdot \mathrm{m}^{-2}$, but with reduced toxicity. Since patients with recurrent small cell lung cancer have a poor prognosis, they benefit especially from good tolerability.

KEYWORDS: Second-line therapy, small cell lung cancer, topotecan

0 mall cell lung cancer (SCLC) is considered to be among the most chemosensitive solid tumours [1]. With combination chemotherapy, such as platinum/etoposide or cyclophosphamide/doxorubicin/etoposide, objective response rates of $20-90 \%$ are observed, with a median survival of $\sim 10$ months. However, the majority of patients will experience tumour recurrence after successful therapy [2-4]. The prognosis with second-line treatment was analysed by HUISMAN et al. [5] from 21 published phase II studies, including 1,749 patients showing response rates of $20 \%$. Response to second-line therapy most likely depends on response to first-line treatment and length of the treatment-free interval. Patients developing disease progression within 3 months after first-line therapy are classified as refractory. Patients with disease progression $>3$ months after the last treatment of first-line therapy, which has induced an objective response, are classified as sensitive [3]. Since refractory patients have a smaller chance of responding to any drug than sensitive patients, stratification between sensitive and refractory patients is necessary to describe the efficacy of a tested regimen. Topotecan (Hycamtin ${ }^{\circledR}$; GlaxoSmithKline, Munich, Germany) is a specific inhibitor of the nuclear enzyme topoisomerase I, which interferes with DNA replication and transcription. Inhibition of this enzyme produces lethal DNA damage [6]. Topotecan was reported to be effective as secondline treatment for SCLC [7]. In a randomised phase III study, topotecan $\left(1.5 \mathrm{mg} \cdot \mathrm{m}^{-2} i . v\right.$., days $1-5$, every 21 days) was at least as effective as the threedrug regimen of cyclophosphamide $1,000 \mathrm{mg} \cdot \mathrm{m}^{-2}$, doxorubicin $45 \mathrm{mg} \cdot \mathrm{m}^{-2}$ and vincristine $2 \mathrm{mg}$ (CAV). Response rate was $24.3 \%$ in the topotecan arm and $18.3 \%$ in the CAV arm. Median survival was 25 weeks for topotecan and 24.7 weeks for CAV. The present study demonstrated that topotecan has significant advantages in controlling disease-related symptoms [8]. In three studies, a total of 264 evaluable patients with recurrent SCLC were stratified as either refractory (126 patients) or sensitive (138 patients), according to their response to first-line therapy. All patients received i.v. topotecan $1.5 \mathrm{mg} \cdot \mathrm{m}^{-2}$ on days $1-5$, every 21 days. The efficacy is summarised in table 1 [9-11]. The most frequent adverse event of the $1.5 \mathrm{mg} \cdot \mathrm{m}^{-2} \cdot$ day $^{-1}$ regimen in all studies was neutropenia grade $3 / 4$. VON PAWEL et al. [12] reported an incidence of grade 4 neutropenia in $67.3 \%$ of patients $(32.5 \%$ of
AFFILIATIONS

*Ludwig Maximilians University, Klinikum der Universität, Innenstadt, München,

\# Dept of Pneumology and Thoracic Surgery, Krankenhaus Großhansdorf, Großhansdorf,

"Dept of Internal Medicine, Robert Koch Klinik, Leipzig,

${ }^{+}$Asklepios Fachkliniken, Robert Koch Allee 2, Gauting,

${ }^{\S}$ Dept of Internal Medicine, St Vincentius Krankenhäuser, Karlsruhe, ${ }^{f}$ Dept of Hematology and Oncology, St Franziskus Hospital, Flensburg, **Medical Dept, University of Bonn, Bonn,

\#\#Bezirksklinikum Obermain, Kutzenberg, Ebensfeld, and "Dept of Internal Medicine II, Clemenshospital, Münster, Germany.

CORRESPONDENCE

R.M. Huber

Ludwig Maximilians Universität

Klinikum der Universität

Innenstadt

Ziemssenstrasse 1

80336 München

Germany

Fax: 498951604905

E-mail: Huber@med.uni-

munchen.de

Received:

February 102005

Accepted after revision:

January 292006

SUPPORT STATEMENT

The present study was supported by an unrestricted grant from

GlaxoSmithKline, Munich, Germany.

European Respiratory Journal Print ISSN 0903-1936 Online ISSN 1399-3003 
courses) in their phase II study [12] and 70.2\% (38.7\% of courses) of patients in their phase III study [8]. ARDIZZONI et al. [11] reported grade 4 neutropenia in $46.9 \%$ of courses. Grade 4 thrombocytopenia was also shown in $8-11 \%$ of courses [11, 12]. Infection associated with grade 4 neutropenia occurred in $28 \%$ of patients and $8.7 \%$ of courses in the topotecan arm of a previous comparative phase III trial, along with four treatment-related deaths (3.7\% of patients) [8]. ARDIZZONI et al. [11] observed infection in $6 \%$ of courses and one treatment-related death. PEREZSOLER et al. [13] reported a lower incidence of haematological toxicity when topotecan was administered in a dose of $1.25 \mathrm{mg} \cdot \mathrm{m}^{-2}$ i.v. on days $1-5$ in patients with SCLC refractory to etoposide/platinum. In $28 \%$ of courses, grade 4 neutropenia was observed, but there were no episodes of neutropenic fever and no treatment-related deaths [13].

The objective of this multicentre phase II trial was to evaluate prospectively the efficacy and safety of topotecan starting with a starting dose of $1.25 \mathrm{mg} \cdot \mathrm{m}^{-2}$ and with dose adjustment in accordance with toxicity. Patients with recurrent or refractory SCLC were stratified according to pre-treatment with a platinum-containing or platinum-free regimen and their response to pre-treatment.

\section{PATIENTS AND METHODS \\ Patient eligibility}

Patients with histologically and/or cytologically documented SCLC, which has recurred or progressed after first-line chemotherapy, were eligible. Further inclusion criteria were: bi-dimensional measurable disease (minimum size of lesion= $2 \times 2 \mathrm{~cm}$ ); male or female patients aged 18-75 yrs; Eastern Cooperative Oncology Group (ECOG) performance status $\leqslant 2$; written informed consent according to the local institutional ethics committee requirements; leukocyte count $\geqslant 4,000$ cells. $\mu \mathrm{L}^{-1}$; platelet count $\geqslant 100,000 \cdot \mu \mathrm{L}^{-1}$; haemoglobin concentration $\geqslant 9.0 \mathrm{~g} \cdot \mathrm{dL}^{-1}$; and creatinine clearance $\geqslant 60 \mathrm{~mL} \cdot \mathrm{min}^{-1}$.

\begin{tabular}{|c|c|c|c|c|c|c|}
\hline First author [ref.] & Subjects $n$ & CR & PR & OR \% & SD \% & $\begin{array}{l}\text { Survival } \\
\text { weeks }\end{array}$ \\
\hline \multicolumn{7}{|l|}{ ECKHARDT [9] } \\
\hline Refractory & $38^{\circ}$ & & 1 & 2.6 & 45 & 20.4 \\
\hline Sensitive & $36^{+}$ & 3 & 4 & 19.4 & 36 & 26.6 \\
\hline Total & 74 & & & 10.8 & 40.5 & NR \\
\hline \multicolumn{7}{|l|}{ Von PAWEL [10] } \\
\hline Refractory & $41^{\circ}$ & & 1 & 2.4 & NR & 16.3 \\
\hline Sensitive & $57^{+}$ & 1 & 7 & 14.0 & NR & 25.7 \\
\hline Total & 98 & & & 9.2 & 27 & 21.6 \\
\hline \multicolumn{7}{|l|}{ ARDIZZONI [11] } \\
\hline Refractory & $47^{\circ}$ & 1 & 2 & 6.4 & 40 & 18.8 \\
\hline Sensitive & $45^{+}$ & 6 & 11 & 37.8 & 31 & 27.6 \\
\hline Total & 92 & & & 21.7 & 35.9 & 21.6 \\
\hline
\end{tabular}

CR: complete response; PR: partial response; OR: odds ratio; SD: stable disease; NR: not reported. ${ }^{\#}$ : median. ${ }^{\bullet}$ : patients who failed to respond or progressed within 90 days of first-line therapy were termed refractory; ${ }^{+}$: patients who relapsed after 90 days after first-line therapy were termed sensitive.
Exclusion criteria included: pre-treatment with a topoisomerase I inhibitor; more than one pre-treatment; pregnant or lactating females; history of neoplasm other than SCLC; serious concomitant medical conditions; dementia; surgery within 2 weeks before study entry; and participation in any other clinical study within 30 days before study entry.

The present study was approved by the ethical committee of each participating centre.

Descriptive statistical methods were used to assess response evaluation, dose intensity, time to progression and toxicity data. Survival estimates were performed using the KaplanMeier method.

\section{Treatment}

Topotecan was administered as a $30-$ min i.v. infusion at a starting dose of $1.25 \mathrm{mg} \cdot \mathrm{m}^{-2}$ for 5 consecutive days, repeated every 21 days for six cycles. One topotecan dose escalation of $0.25 \mathrm{mg} \cdot \mathrm{m}^{-2}$ was to be performed in the second cycle in the absence of haematological toxicities grade 3 or 4 . Further dose escalations of $0.25 \mathrm{mg} \cdot \mathrm{m}^{-2}$ in the absence of haematological toxicities grade 3 or 4 was left to the discretion of the investigator.

A topotecan dose reduction of $0.25 \mathrm{mg} \cdot \mathrm{m}^{-2}$ was to be performed in case of the following: 1) grade 4 neutropenia lasting 7 days or longer, or complicated by fever or infection; 2 ) platelet count $<25,000 \cdot \mu \mathrm{L}^{-1}$, or neutrophil count $<1,500$ cells $\mu \mathrm{L}^{-1}$ and platelet count $<100,000 \cdot \mu \mathrm{L}^{-1}$ on day 22 ; and 3 ) in case of grade 3 or 4 nonhaematological toxicity (except for nausea, vomiting and alopecia). In any case, the minimum topotecan dose had to be $1.0 \mathrm{mg} \cdot \mathrm{m}^{-2} \cdot \mathrm{day}^{-1}$. No dose reescalation was allowed.

Use of granulocyte colony-stimulating factor (G-CSF) was left to the discretion of the investigator. Duration of the treatment was based on response evaluation which was performed after a minimum of two courses. In case of complete response, treatment was continued for two additional courses. In case of partial response, or stable disease, treatment was continued until disease progression or severe toxicity was observed or for the planned treatment of six cycles. Patients were withdrawn from the current study in case of disease progression or incomplete haematological recovery 2 weeks after scheduled treatment or for other generally accepted reasons. Response and toxicity were evaluated according to the World Health Organization and National Cancer Institute-Common Toxicity Criteria (revised version, 1994) [14].

\section{Study design}

The objectives of the present study were to evaluate response rates, response duration, toxicities, dose-intensity, and median survival of relapsed SCLC treated with topotecan at a starting dose of $1.25 \mathrm{mg} \cdot \mathrm{m}^{-2} \cdot$ day $^{-1}$. Patients were stratified according to pre-treatment with or without platinum, and according to response to pre-treatment (sensitive versus refractory).

According to given treatment, patients were grouped to a "safety", "survival" or "response" collective. The objectives of the current study were analysed within the corresponding groups. Patients $(n=170)$ who received at least one dose of study drug were evaluated by safety analysis. Patients $(n=164)$ 


\section{TABLE 2 Patients characteristics ${ }^{\#}$}

\section{Patients registered}

Assessable for response intention to treat $170(100)$

Assessable for survival

$164(96.5)$

Assessable for toxicity

Age

Median 61 yrs

$<60$ yrs

$66(40.3)$

$\geqslant 60 \mathrm{yrs}$

$98(59.7)$

Sex

Male

$128(78.0)$

Female

$36(22.0)$

ECOG performance status

0 Karnofsky $100 \%$

34 (20.7)

1 Karnofsky $80-90 \%$

$92(56.1)$

2 Karnofsky $60-70 \%$

37 (22.6)

Extent of disease

Limited disease

Extensive disease without distant metastasis

$4(2.4)$

Extensive disease with distant metastasis

No data

38 (23.2)

$120(73.2)$

$2(1.2)$

Liver metastases

Present

59 (36.0)

Absent

$105(64.0)$

Brain metastases

Present

46 (28)

Absent

Best response to first-line treatment

Complete response

$118(72)$

Partial response

31 (18.9)

$95(57.9)$

Stable disease

Progression

Time to relapse after first-line therapy

$<3$ months refractory

$\geqslant 3-<6$ months sensitive

Time to progression after first-line therapy

Median days

Prior anticancer treatment

Prior radiotherapy

Prior surgery

First-line therapy

Platinum-based

Nonplatinum-based

$9(5.5)$

$29(17.7)$

$57(34.8)$

$107(65.2)$

191

$85(51.8)$

$17(10.4)$

$104(63.4)$

$60(36.6)$

First-line chemotherapy regimen

Carboplatin, etoposide, vincristin

$48(29.3)$

Platinum cisplatin or carboplatin, etoposide 36 (21.9)

Carboplatin, taxol, etoposide

7 (4.3)

Adriamycin, cyclophosphamide, vincristine 20 (12.2)

Epirubicin, cyclophosphamide, vincristine 20 (12.2)

Cyclophosphamide, etoposide, adriamycin 12 (7.3)

Other regimes

$21(12.4)$

Number of measurable lesions

1

$69(42.1)$

$50(30.5)$

$33(20.1)$

$12(7.2)$

who had received at least one course of study medication and did not show any serious study deviation (i.e. no measurable disease) were evaluated for survival, demographic data, dose intensity and time to progression. Objective response evaluation was performed in patients $(n=120)$ who received at least two courses of the study drug and had a tumour baseline status with re-evaluation (response collective). In 41 patients, clinical progressive disease or death was observed prior to response re-evaluation after the end of the second cycle. Clinical progressive disease, death or missing response data were regarded as progressive disease, according to a worstcase scenario (intention-to-treat).

Tumour response was judged by each individual centre. Median time to progression and survival were calculated according to the Kaplan-Meier product limit method.

\section{RESULTS}

\section{Patient characteristics}

A total of 170 patients were enrolled from 44 participating centres between February 1998 and June 1999. The last followup was performed in December 2002. It was possible to evaluate all patients for safety analysis. In total, 164 patients were evaluated for survival analysis (two patients did not complete a full course and four patients did not have a bidimensionally measurable lesion). Tumour response, as the primary end-point of the present study, was evaluated in all patients who received at least one dose of the study drug $(\mathrm{n}=170$; intention-to-treat). Of these, 37 patients received less than two courses and seven patients were lost to follow-up. A total of $76.8 \%$ of patients had performance status ECOG $0-1$. The majority of patients $(73.2 \%)$ had distant metastatic disease and $63.4 \%$ of patients had received a platinum-based primary therapy. The overall response rate to primary therapy was $76.8 \%$. In total, $34.8 \%$ of patients were refractory, whereas $65.2 \%$ of patients were sensitive to prior therapy. The median time to progression after first-line therapy was 191 days (table 2).

\section{Dosing}

A total of 514 topotecan courses were received by 164 patients. Of these, $22.6 \%$ of patients $(n=37)$ received only one course of therapy, $2.4 \%(n=4)$ of patients received eight courses and 52 patients $(31.7 \%)$ received two courses. The first cycle was administered to 164 patients and the sixth cycle to 36 patients. In $58.2 \%$ of courses $(n=299)$, the starting dose was maintained. The topotecan dose had to be reduced to $1.0 \mathrm{mg} \cdot \mathrm{m}^{-2} \cdot$ day $^{-1}$ in $8.9 \%(n=46)$ of courses. The targeted dose of topotecan $\left(1.5 \mathrm{mg} \cdot \mathrm{m}^{-2} \cdot \mathrm{d}^{-1}\right)$ was reached in $32.9 \%(\mathrm{n}=169)$ of courses. In the first course, the topotecan dose was administered as a starting dose of $1.25 \mathrm{mg} \cdot \mathrm{m}^{-2}$. day $^{-1}$ to $98.2 \%$ of patients $(\mathrm{n}=161)$. This starting dose was maintained in $46.5 \%$ of patients $(n=59)$ in course two. Dose escalation to $1.5 \mathrm{mg} \cdot \mathrm{m}^{-2}$. day $^{-1}$ of topotecan was performed in $37.8 \%$ of patients $(n=48)$, whereas in $15.7 \%$ $(\mathrm{n}=20)$ it was reduced to $1.0 \mathrm{mg} \cdot \mathrm{m}^{-2} \cdot \mathrm{day}^{-1}$. Protocol deviations, according to dose modification in the second cycle, were noticed in $13.1 \%$ (no dose escalation to $1.5 \mathrm{mg} \cdot \mathrm{m}^{-2}$ ) and $17.0 \%$ (no dose reduction to $1.0 \mathrm{mg} \cdot \mathrm{m}^{-2}$ ) of patients, respectively. While the number of patients who received subsequent courses decreased, the percentage of patients who received an escalated dose rose from $46.7 \%$ (third cycle) to $58.3 \%$ (sixth 
cycle). At the same time, the percentage of patients who received a reduced dose decreased from the third cycle $(13.3 \%)$ to the sixth cycle $(8.3 \%)$, with the exception of the fifth cycle $(14.0 \%)$. The percentage of patients within the third to sixth cycles receiving the starting dose was between $30.2 \%$ (fifth cycle) and $40.0 \%$ (third cycle). Median dose intensity of all administered cycles was $1.25 \mathrm{mg} \cdot \mathrm{m}^{-2} \cdot$ day $^{-1}$ (table 3 ).

\section{Efficacy}

Response to treatment

A total of 170 patients were evaluated for their response (intention to treat). The overall response rate was $14.1 \%$ with one complete response and $23(13.5 \%)$ partial responses. Stable disease was observed in $25.9 \%$ and progressive disease in $60 \%$ of patients. No difference in response rates was seen between patients with or without platinum-containing pre-treatment, with overall response rates of 14.9 and $12.7 \%$, respectively. However, patients who had been refractory to primary therapy achieved a lower response rate and a higher rate of disease stabilisation to topotecan therapy. The overall response rate was $8.6 \%$ in refractory patients versus $17.1 \%$ in sensitive patients and stable disease was observed in 36.2 and $20.7 \%$ of patients, respectively (table 4). Among all responding patients, the median time to response was 7.2 (range 2.914.7) weeks. There was no significant difference between patients with platinum-containing and platinum-free pretreatment at 8.1 versus 6.6 weeks $(p=0.8952)$, respectively. In refractory patients, time to response was significantly longer at 12.4 weeks versus 6.4 weeks $(p=0.0260)$. As shown in table 5, median duration of response was 13.6 (3.0-47.9) weeks and was not significantly different among the subgroups. Median time to progression for all patients was 8.0 (0.1-53.6) weeks. An analysis according to stratification parameters showed no significant differences between sensitive versus refractory patients.

\section{Survival}

It was possible to evaluate 164 patients for survival. The median survival time was 23.4 weeks (95\% confidence interval (CI) 19.0-27.0 (0.9-92.4) weeks) and mean survival was 28.3 weeks (fig. 1). Median survival time for patients with a

\begin{tabular}{|c|c|c|c|c|}
\hline TABLE 3 & $\begin{array}{l}\text { Dose ir } \\
\text { study } p\end{array}$ & $\begin{array}{l}\text { ity and ao } \\
\text { ths }\end{array}$ & stered cc & $s$ in the \\
\hline \multirow[t]{2}{*}{ Course } & \multicolumn{4}{|c|}{ Administered dose $\mathbf{m g} \cdot \mathrm{m}^{-2}$} \\
\hline & 1.00 & 1.25 & 1.5 & $>1.5$ \\
\hline 1 & $2(1.2)$ & $161(98.2)$ & $1(0.6)$ & $0(0.0)$ \\
\hline 2 & $20(15.7)$ & $59(46.5)$ & $48(37.8)$ & $1(0.8)$ \\
\hline 3 & $10(13.3)$ & $30(40.0)$ & $35(46.7)$ & $1(1.3)$ \\
\hline 4 & $5(8.2)$ & $22(36.1)$ & $34(55.7)$ & $2(3.3)$ \\
\hline 5 & $6(14.0)$ & $13(30.2)$ & $22(55.8)$ & $2(4.7)$ \\
\hline 6 & $3(8.3)$ & $12(33.3)$ & $21(58.3)$ & $1(2.8)$ \\
\hline 7 & $0(0.0)$ & $1(25.0)$ & $3(75.0)$ & $0(0.0)$ \\
\hline 8 & $0(0.0)$ & $1(25.0)$ & $3(75.0)$ & $0(0.0)$ \\
\hline
\end{tabular}

complete and partial response, stable disease or progressive disease was 43.4, 28.6 and 26.0 weeks, respectively. Stratified according to pre-treatment and response to pre-treatment, no differences in median survival time could be detected. Median survival time of 62 weeks was found in patients with an objective response to topotecan and nonplatinum-containing pre-treatment.

After 1 yr 25 patients were alive according to a 1-yr survival rate of $15.2 \%$.

\section{Toxicity}

A total of 170 patients received at least one dose of topotecan and were evaluable for toxicity. Treatment delays of $>14$ days due to haematological toxicity were observed in five patients. Delays of $>7$ days due to toxicity or management reasons were performed in $11.7 \%$ of courses. Therapy had to be stopped in nine patients. All cases were associated with myelosuppression. One treatment-related death was observed. This patient, with poor performance status, declined hospitalisation despite grade 4 neutropenia and thrombocytopenia. Major side-effects were neutropenia and leukopenia, whereas anaemia and thrombocytopenia were less common. Grade 3 and 4 neutropenia occurred in 27.7 and $27.6 \%$ of patients, and in 31.5 and $6.9 \%$ of treatment courses, respectively. G-CSF was administered in $21.2 \%$ of patients in $11.5 \%$ of treatment courses. Febrile neutropenia was observed in $0.8 \%$ of courses. The incidence of grade 3 and 4 thrombocytopenia was $10.3 \%$ and $5.0 \%$ of treatment courses (23.5 and $13.5 \%$ of patients), respectively. In total, $10 \%$ of patients received a platelet substitution in $3.3 \%$ of treatment courses. Anaemia grade 3 and 4 was less common ( $5.5 \%$ and $0.6 \%$ of all courses, respectively); in $3.6 \%$ of courses, erythrocytes had to be substituted. No evidence of cumulative haematological toxicity was observed. Haematological toxicity among the subgroups is presented in table 6 demonstrating lower rates of neutropenia and thrombocytopenia in refractory patients. In patients without platinum-containing pretreatment, grade 3 and 4 anaemia was more frequent. Nonhaematological toxicities of grade 3 and 4 , which were observed in $>1 \%$ of patients, included: pain (5.9\%), infection $(4.7 \%)$, nausea $(1.8 \%)$ and fever $(1.8 \%)$.

\section{DISCUSSION}

Despite the high chemosensitivity of SCLC, the majority of patients have a relapse after induction chemotherapy. The prognosis of patients with recurrent disease remains poor. The goals of chemotherapy in this patient population were to obtain maximum control of disease symptoms, prevent serious complications and increase survival without diminishing quality of life $[1,4,5]$. The current prospective study is the first trial in which an individual dose adjustment strategy with a reduced topotecan starting dose was evaluated in order to reduce toxicity, a procedure which is in close relationship to the clinical practice in relapsed SCLC.

A prospective analysis of the haematological toxicity profile of topotecan, administered at a dose of $1.25 \mathrm{mg} \cdot \mathrm{m}^{-2} \cdot$ day $^{-1}$ on days 1-5 to pre-treated patients with ovarian cancer, revealed that the severity of topotecan-induced thrombocytopenia is maximal after the first cycle, but significantly decreases after the second cycle without dose reductions [15]. FIELDS et al. [16] performed a retrospective analysis of second-line patients with 
TABLE 4 Responses according to stratification

\begin{tabular}{|c|c|c|c|c|c|}
\hline & \multirow[t]{2}{*}{ All patients } & \multicolumn{2}{|c|}{ Platinum pre-treatment } & \multicolumn{2}{|c|}{ Response to pre-treatment ${ }^{\#}$} \\
\hline & & Yes & No & Sensitive & Refractory \\
\hline Subjects $n$ & 170 & 107 & 63 & 111 & 58 \\
\hline Complete response & 0.6 & 0.9 & 0.0 & 0.9 & 0.0 \\
\hline Partial response & 13.5 & 14.0 & 12.7 & 16.2 & 8.6 \\
\hline Progressive disease & 60.0 & 59.8 & 60.3 & 62.2 & 55.2 \\
\hline 95\% $\mathrm{Cl}$ for response & & $30.8-50.1$ & $27.6-52.8$ & $28.8-47.5$ & $31.7-58.5$ \\
\hline
\end{tabular}

SCLC treated with the standard topotecan dose. In 110 patients, the dose was reduced to $\leqslant 1.25 \mathrm{mg} \cdot \mathrm{m}^{-2} \cdot$ day $^{-1}$ due to haematological toxicity. Response rates and survival in the reduced dose population were similar to the results of the standard dose population [16].

The presented results demonstrate that treatment with the reduced topotecan starting dose of $1.25 \mathrm{mg} \cdot \mathrm{m}^{-2} \cdot$ day $^{-1}$ and an individual dose adjustment is equi-effective to the efficacy of the standard dose of $1.5 \mathrm{mg} \cdot \mathrm{m}^{-2} \cdot$ day $^{-1}$. VON PAWEL and coworkers $[8,16]$ reported a median survival of 25 weeks for 98

\begin{tabular}{|c|c|c|}
\hline \multirow[t]{2}{*}{ TABLE 5} & \multicolumn{2}{|c|}{$\begin{array}{l}\text { Response duration, time to progression and } \\
\text { survival }\end{array}$} \\
\hline & Patients & Weeks \\
\hline \multicolumn{3}{|c|}{ Response duration } \\
\hline All & 24 & $13.6(3.0-47.9)$ \\
\hline Platinum +PT & 16 & $12.1(3.0-47.9)^{\#}$ \\
\hline Platinum -PT & 8 & $19.4(7.3-40.9)$ \\
\hline Sensitive & 19 & $15.0(3.0-47.9)^{\bullet}$ \\
\hline Refractory & 5 & $13.0(4.7-27.1)$ \\
\hline \multicolumn{3}{|c|}{ Time to progression } \\
\hline All & 164 & $8.0(0.1-53.6)$ \\
\hline Platinum +PT & 104 & $7.9(2.1-53.6)^{+}$ \\
\hline Platinum -PT & 60 & $9.6(0.1-48.0)$ \\
\hline Sensitive & 107 & $8.0(2.1-53.6)^{5}$ \\
\hline Refractory & 57 & $9.6(0.1-41.3)$ \\
\hline \multicolumn{3}{|l|}{ Survival } \\
\hline All & 164 & $23.4(0.9-92.4)$ \\
\hline Platinum +PT & 104 & $23.4(0.9-92.4)^{f}$ \\
\hline Platinum -PT & 60 & $22.9(1.1-83.1)$ \\
\hline Sensitive & 107 & $22.4(0.9-92.4)^{\# \#}$ \\
\hline Refractory & 57 & $23.7(1.1-85.7)$ \\
\hline \multicolumn{3}{|c|}{ 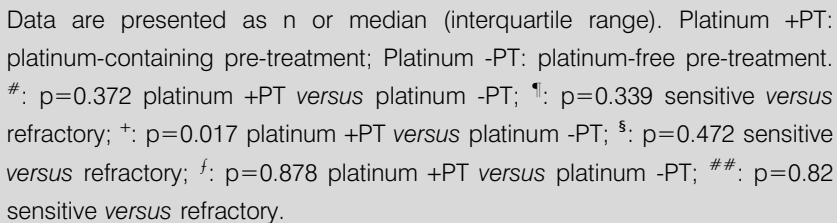 } \\
\hline
\end{tabular}

patients receiving the i.v. regimen of $1.5 \mathrm{mg} \cdot \mathrm{m}^{-2} \cdot \mathrm{day}^{-1}$ in the phase II and 107 patients in the phase III study; in the present study, the median survival was 23.4 weeks. Of note, in these trials, mostly sensitive patients were included [8, 12].

The greater tolerability of this regimen is also reflected in the reduced rate of haematological toxicities compared with recently reported trials, where topotecan was given at a standard dose. In the current trial, grade 4 neutropenia and thrombocytopenia occurred in 6.9 and $5 \%$ of courses, respectively, and febrile neutropenia was observed in only $0.8 \%$. In other studies using the standard i.v. dose of topotecan in relapsed SCLC, grade 4 neutropenia and thrombocytopenia were observed in $32.5-46.9 \%$ and $7.7-11.9 \%$ of courses, respectively $[8,11]$. Febrile neutropenia occurred in $3.3-6 \%$ of i.v. topotecan courses. Nonhaematological toxicities were mild and did not influence patients' well-being. Notably, grade 3 and 4 neutropenia and thrombocytopenia is less frequent in refractory compared with sensitive patients. This is very important for refractory patients, since the clinical benefit does not seem to be associated with a higher toxicity and justifies therapy in this special patient group.

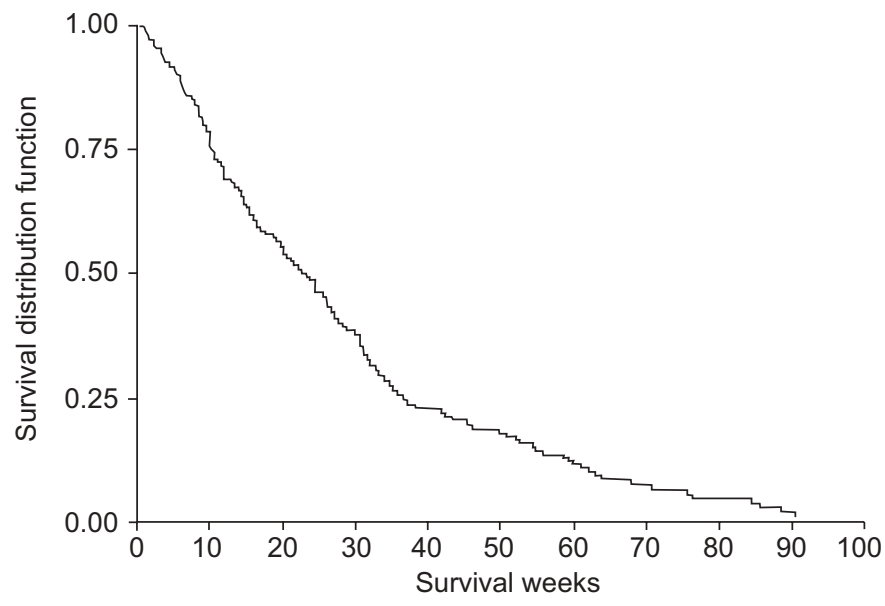

FIGURE 1. Kaplan-Meier plot of overall survival $(n=164)$. Median survival: 23.4 weeks. 


\begin{tabular}{|c|c|c|c|c|c|}
\hline & All & \multicolumn{2}{|c|}{ Platinum pre-treatment } & \multicolumn{2}{|c|}{ Response to pre-treatment } \\
\hline Subjects & 170 & 104 & 60 & 107 & 57 \\
\hline Leukopenia & $44.1 / 17.6$ & $44.3 / 16.3$ & $45.5 / 21.2$ & $47.7 / 22.4$ & $38.6 / 10.5$ \\
\hline Thrombopenia & $23.5 / 13.5$ & $25.0 / 12.5$ & $20.1 / 16.6$ & $12.2 / 16.8$ & $15.8 / 8.8$ \\
\hline Anaemia & $16.0 / 1.7$ & $14.4 / 1.9$ & $18.4 / 1.6$ & $14.0 / 2.8$ & $19.3 / 0$ \\
\hline
\end{tabular}

Median dose intensity of all administered cycles was $1.25 \mathrm{mg} \cdot \mathrm{m}^{-2} \cdot \mathrm{day}^{-1}$. In $58.2 \%$ of all courses, the starting dose was maintained and in $32.9 \%$ of courses the dose was escalated to $1.5 \mathrm{mg} \cdot \mathrm{m}^{-2} \cdot$ day $^{-1}$. Only $8.9 \%$ of courses had to be reduced due to haematological toxicity compared with phase II studies with a standard topotecan dosage, where dose reductions of $16-19 \%$ were reported $[11,12]$.

The overall response rate of $14.1 \%$ obtained in the present study is comparable to recently published reports using i.v. topotecan in the standard dosage (table 1). As expected, the response rate was higher in sensitive patients $(17.1 \%)$ than in refractory patients $(8.6 \%)$, and median time to response was longer for refractory patients (12.4 weeks) than for sensitive patients (6.4 weeks). This is in accordance with reports by ARDIZZONI et al. [11] and PEREZ-SOLER et al. [13]. In contrast, no difference was seen between patients with or without platinum-containing pre-treatment indicating the lack of cross-resistance to platinum. PEREZ-SOLER et al. [13] reported the responses to topotecan in etoposide-refractory patients and concluded that it may overcome etoposide resistance. Interestingly, in $36.2 \%$ of refractory patients and $20.7 \%$ of sensitive patients, stabilisation of disease was observed. As shown by CESANO et al. [17], stable disease represents a potential clinical benefit, since stable disease has the same survival benefit as a partial response versus progressive disease. Primary progression rate also provides support for a clinical benefit; it shows no difference between the four subgroups and is not higher in refractory patients.

Median duration of response was 13.6 weeks and median time to progression was 8.0 weeks for all patients. Patients with platinum-free pre-treatment had an advantage in median time to progression compared with patients with platinum-containing pre-treatment. Median time to progression was 9.6 weeks versus 7.9 weeks in these groups (table 5). The results concerning pre-treatment are difficult to compare with other studies, as the distinction between platinum-containing and platinum-free pre-treatment is not reported.

The median survival was 23.4 weeks and 1-yr survival was $15.2 \%$ without any differences between the subgroups. The survival data for all patients are comparable to reports using the standard topotecan dosage in phase II and III trials [9-11]. ARDIZZONi et al. [11] reported longer survival data for sensitive than for refractory patients (6.9 versus 4.7 months). In the present study, survival data of refractory patients are similar to survival in sensitive patients (23.7 versus 22.4 weeks). High rate of disease stabilisation, especially in the refractory patients' group, may contribute to better median survival of refractory patients in the current study. This is in agreement with previous reports in which survival of patients with partial response was comparable with survival of patients with stable disease following topotecan therapy of SCLC and ovarian cancer [17]. Stable disease is a valid end-point provided that symptom palliation is achieved and treatment-related toxic side-effects are mild.

A meta-analysis of four multicentre trials treating patients with relapsed SCLC with topotecan at a starting dose of $1.5 \mathrm{mg} \cdot \mathrm{m}^{-}$ ${ }^{2}$. day $^{-1}$ suggests that dose reductions due to haematological toxicity $\left(\leqslant 1.25 \mathrm{mg} \cdot \mathrm{m}^{-2} \cdot \mathrm{day}^{-1}\right)$ are not correlated with decreased efficacy. The response rate and median survival in the reduced dose population was $17.3 \%$ and 29.9 weeks, respectively, compared with $18.1 \%$ and 28.6 weeks in the standard dose population. These results support those of the present study, indicating that moderate topotecan dose reductions can counterbalance the haematological toxicity but are not associated with reduced efficacy [16].

To the best of the present authors' knowledge, this is the first prospective trial in relapsed small cell lung cancer which shows a positive impact on safety parameters of topotecan therapy at a reduced starting dose with an individual dose adjustment strategy. It is of special interest that this impact is in association with the same efficacy compared with standard topotecan regimens. These results demonstrate that patients with sensitive and refractory relapsed small cell lung cancer can benefit from chemotherapy and that treatment-related side-effects are manageable by individual dose titration.

\section{ACKNOWLEDGEMENTS}

The authors would like to thank the clinical research organisation GKM Gesellschaft für Therapieforschung (Munich, Germany) for the monitoring and statistical analysis performed in the current study.

\section{REFERENCES}

1 Carney DN., Shepherd FA. Treatment of SCLC: chemotherapy. In: Hansen $\mathrm{HH}$, ed. Textbook of Lung Cancer. London, Martin Dunitz Ltd, 2000; pp. 261-272. 
2 Roth BJ, Johnson DH, Einhorn LH, et al. Randomized study of cyclophosphamide, doxorubicin, and vincristine versus etoposide and cisplatin versus alternation of these two regimens in extensive small-cell lung cancer: a phase III trial of the Southeastern Cancer Study Group. J Clin Oncol 1992; 10: 282-291.

3 Giaccone G, Splinter TAW, Debruyne C, et al. Randomized study of paclitaxel-cisplatin versus cisplatin-teniposide in patients with advanced non-small-cell lung cancer. J Clin Oncol 1998; 16: 2133-2141.

4 Murren J, Glatstein E, Pass HI, et al. Small cell lung cancer. In: De Vita VT Jr, Hellman S, Rosenberg SA, eds. Cancer: Principles and Practice of Oncology. Philadelphia, Lippincott, Williams and Wilkins, 2001; pp. 983-1018.

5 Huisman C, Postmus PE, Giaccone G, et al. Second-line chemotherapy and its evaluation in small cell lung cancer. Cancer Treat Rev 1999; 25: 199-206.

6 Chen AY, Liu LF. DNA topoisomerases: essential enzymes and lethal targets. Annu Rev Pharmacol Toxicol 1994; 34: 191-218.

7 Rocha Lima CM, Sherman CA, Brescia FJ, et al. Irinotecan/ gemcitabine combination chemotherapy in pancreatic cancer. Oncology (Huntington, NY) 2001; 15: 46-51.

8 Von Pawel J, Schiller JH, Shepherd FA, et al. Topotecan versus cyclophosphamide, doxorubicin, and vincristine for the treatment of recurrent small-cell lung cancer. J Clin Oncol 1999; 17: 658-667.

9 Eckardt J, Gralla R, Palmer MC, et al. Topotecan (T) as second-line therapy in patients (pts) with small cell lung cancer (SCLC): a phase II study. Ann Oncol 1996; 7: 107.

10 Von Pawel J, Depierre A, Hans K, et al. Topotecan (Hycamtin(TM)) in small cell lung cancer (SCLC) after failure of first line therapy: multicentre phase II study. Eur J Cancer 1997; 33: Suppl. 8, 1038a.

11 Ardizzoni A, Hansen $\mathrm{H}$, Dombernowsky $\mathrm{P}$, et al. Topotecan, a new active drug in the second-line treatment of small-cell lung cancer: a phase II study in patients with refractory and sensitive disease. The European Organization for Research and Treatment of Cancer Early Clinical Studies Group and New Drug Development Office, and the Lung Cancer Cooperative Group. J Clin Oncol 1997; 15: 2090-2096.

12 Von Pawel J, Gatzemeier U, Pujol JL, et al. Phase II comparator study of oral versus intravenous topotecan in patients with chemosensitive small-cell lung cancer. J Clin Oncol 2001; 19: 1743-1749.

13 Perez-Soler R, Glisson BS, Lee JS, et al. Treatment of patients with small-cell lung cancer refractory to etoposide and cisplatin with the topoisomerase I poison topotecan. J Clin Oncol 1996; 14: 2785-2790.

14 Miller AB, Hoogstraten B, Staquet M, et al. Reporting results of cancer treatment. Cancer 1981; 47: 207-214.

15 Goldwasser F, Buthaud X, Gross M, et al. Decreased topotecan platelet toxicity with successive topotecan treatment cycles in advanced ovarian cancer patients. Anticancer Drugs 1999; 10: 263-265.

16 Fields SZ, Eckardt JR, Zhang L, et al. Efficacy of reduced dose of IV topotecan (T) in relapsed small cell lung cancer (SCLC) patients. Lung Cancer 2000; 29: Suppl. 1, 10.

17 Cesano A, Lane SR, Poulin R, et al. Stabilization of disease as a useful predictor of survival following second-line chemotherapy in small cell lung cancer and ovarian cancer patients. Int J Oncol 1999; 15: 1233-1238. 